\title{
Mimicking the tumour microenvironment of chronic lymphocytic leukaemia in vitro critically depends on the type of B-cell receptor stimulation
}

\author{
Ans Rombout ${ }^{1}$, Sofie Lust ${ }^{2}$, Fritz Offner ${ }^{2}$, Evelien Naessens ${ }^{1}$, Bruno Verhasselt ${ }^{1}$ and Jan Philippé ${ }^{\star}, 1$ \\ ${ }^{1}$ Department of Clinical Chemistry, Microbiology and Immunology, Ghent University, Ghent University Hospital, De Pintelaan 185, \\ B-9000 Ghent, Belgium and 'Department of Internal Medicine, Hematology, Ghent University Hospital, De Pintelaan 185, B-9000 \\ Ghent, Belgium
}

Background: The B-cell receptor (BCR) has a key role in the cross-talk between chronic lymphocytic leukaemia (CLL) cells and the tissue microenvironment, which favours disease progression by promoting proliferation and drug resistance. In vitro studies on downstream signalling and functional effects of CLL BCR ligation often report contradictory results, in part owing to the lack of a standardised stimulation protocol. Our aim was to define a biologically relevant and robust in vitro stimulation method with regard to cellular phenotypic and transcriptional responses.

Methods: We evaluated mRNA (FOS, MYC, LPL) and protein (CD54, CD19, CD62L, CD184) expression of genes modulated by $\mathrm{BCR}$ triggering in immunoglobulin heavy-chain variable region genes (IGHV)-mutated and -unmutated CLL cells, after stimulation using soluble or immobilised anti-lgM antibodies from different suppliers.

Results: The effect of BCR stimulation on gene and protein expression was comparable in all CLL patients, irrespective of IGHV mutation status. However, immobilised anti-IgM stimulation elicited clear and robust changes in gene and protein expression, whereas the response to soluble anti-IgM was far less obvious.

Conclusions: These data indicate that the method of BCR stimulation is of major importance regarding responsiveness of CLL cells in the context of the tumour microenvironment, whereas genetic differences in the BCR pathway are less critical.

Chronic lymphocytic leukaemia (CLL) is characterised by the accumulation of clonal $\mathrm{CD}^{+} / \mathrm{CD} 23^{+}$B lymphocytes in peripheral blood $\left(>5.0 \times 10^{6} \mu \mathrm{l}^{-1}\right)$, bone marrow and lymphoid organs. The clinical course of CLL patients is highly variable: Some patients live for decades after diagnosis, whereas others progress rapidly despite aggressive treatment (Chiorazzi et al, 2005). Major progress has been made in the identification of genetic and cellular markers, which predict disease progression. Several prognostic factors in CLL, such as mutation status of the immunoglobulin heavy-chain variable region genes (IGHV) (Damle et al, 1999; Hamblin et al, 1999), zeta-chain-associated protein kinase 70
(ZAP70) (Crespo et al, 2003; Wiestner et al, 2003), lipoprotein lipase (LPL) (Heintel et al, 2005; van't Veer et al, 2006) and chemokine ligand 3 and 4 (CCL3/4) expression (Burger et al, 2009; Sivina et al, 2011) are associated with B-cell receptor (BCR) activation, suggesting that BCR signalling has a critical role in CLL pathogenesis. Also, the biased VH gene repertoire over CLL cases supports the idea of antigen-driven selection and expansion of CLL clones via antigens present in the microenvironment (Capello et al, 2004; Messmer et al, 2004). Activation of the BCR of normal B cells predominantly occurs in the lymphatic tissues and triggers a cascade of signalling events that cause B-cell selection,

*Correspondence: Professor J Philippé; E-mail: Jan.Philippe@UGent.be

Revised 9 December 2015; accepted 20 January 2016; published online 25 February 2016

(c) 2016 Cancer Research UK. All rights reserved 0007-0920/16 
proliferation, differentiation and antibody production (Niiro and Clark, 2002). In CLL and other B-cell malignancies, the leukaemic cells critically depend on interactions with bystander cells in the tissue microenvironment to acquire survival and growth signals. The BCR has a central role in this cross-talk with the tumour microenvironment, involving critical downstream kinases such as Lyn, Syk and Btk. In addition, CLL cells secrete cytokines and chemokines upon BCR activation, which attract accessory cells, such as $\mathrm{T}$ cells, which further contribute to the maintenance and expansion of the leukaemic clone (Burger et al, 2009; Herishanu et al, 2011; Burger and Gribben, 2014). Promising results obtained in clinical trials, evaluating new inhibitors targeting this CLL microenvironment cross-talk, further emphasise the central role for BCR signalling in CLL (Quiroga et al, 2009; Hoellenriegel et al, 2011; de Rooij et al, 2012).

As BCR signalling is assumed to have such a crucial role in CLL pathogenesis, stimulation of the BCR in vitro is relevant to unravel the biology of the CLL cell and its surrounding microenvironment. However, controversial data have been published concerning the change in gene expression and functional consequences upon BCR stimulation. Furthermore, some studies show that cross-linking the surface IgM receptor results in a heterogeneous response among CLL cases, correlating with prognostic indicators of progressive disease (Deglesne et al, 2006; Guarini et al, 2008; Quiroga et al, 2009; Vlad et al, 2009). We and others did, however, not observe a differential response upon BCR stimulation between prognostic classes of CLL (Deglesne et al, 2006; Pallasch et al, 2008; Pede et al, 2013). In a previous study, we investigated the transcriptional response of CLL cells upon IgM stimulation of the BCR using antiIgM-coated polyacrylamide beads and found that both IGHVmutated and -unmutated CLL cells responded with increased expression of FOS, MYC and other BCR activation-associated genes (Pede et al, 2013). Here, we wanted to evaluate whether the observed response was limited to the use of this particular reagent, and if we could reach out for a standardised protocol of BCR stimulation. We compared different stimulation protocols and found a marked difference in respect to immobilised vs soluble triggers of the BCR. We could confirm our previously published data with different reagents and propose a BCR stimulation protocol, to mimic what CLL cells experience in the lymphoid microenvironment.

\section{MATERIALS AND METHODS}

Ethics statement. This study was approved by the Ghent University Hospital Ethics Committee and conducted according to the principles expressed in the Declaration of Helsinki. Patient samples were obtained after written informed consent.

Patients sample collection and characterisation. Blood samples were collected from patients diagnosed with CLL at our institution, which were either untreated or had not received treatment for at least 6 months prior to the time of blood collection. Peripheral blood mononuclear cells (PBMC) were isolated on a Lymphoprep (Nycomed, Oslo, Norway) layer, and used fresh or frozen viably in fetal bovine serum (FBS, Hyclone, Thermofisher Scientific, Waltham, MA, USA) supplemented with 10\% dimethylsulphoxide (Sigma-Aldrich (SA), Diegem, Belgium) for storage in liquid nitrogen. Cryopreservation did not compromise functional experiments after thawing (Pede et al, 2013). Characteristics of the patients included are summarised in Table 1. Determination of IGHV mutation status, ZAP70 protein expression and cytogenetic analysis were performed as previously described (Van Bockstaele et al, 2007). CD38 expression was evaluated by flow cytometric staining according to van Dongen et al (2012). Measurements were performed on a FACSCanto II flow cytometer (BD Biosciences,
Erembodegem, Belgium). CD38 expression was deemed positive if $30 \%$ of the cells stained positive with a cutoff set on the T-cell population.

Cell culture and BCR stimulation. After isolation or thawing, PBMCs were cultured overnight at a density of $1.0 \times 10^{7}$ cells ml $^{-1}$ in Iscove's modified Dulbecco's medium (IMDM, Invitrogen, Merelbeke, Belgium) supplemented with penicillin $\left(100 \mathrm{U} \mathrm{ml}^{-1}\right.$, Invitrogen), streptomycin $\left(100 \mu \mathrm{g} \mathrm{ml}^{-1}\right.$, Invitrogen) and $10 \% \mathrm{FBS}$ in a humidified atmosphere of $37^{\circ} \mathrm{C}$ containing $7 \%(\mathrm{v} / \mathrm{v}) \mathrm{CO}_{2}$. After overnight incubation, $\mathrm{CD} 19^{+}$cells were selected by negative depletion using EasySep technology (Stem Cell Technologies, Vancouver, Canada) according to the manufacturer's instructions. Purity was assessed by flow cytometry and was at least $95.8 \%$ (data not shown).

Cells were cultured at a density of $1.0 \times 10^{7}$ cells ml $^{-1}$ in complete IMDM medium in 96-well plates in a humidified atmosphere of $37^{\circ} \mathrm{C}$ containing $7 \%(\mathrm{v} / \mathrm{v}) \mathrm{CO}_{2}$. BCR stimulation was performed with $10 \mu \mathrm{g} \mathrm{ml}^{-1}$ or $100 \mu \mathrm{g} \mathrm{ml}^{-1}$ of rabbit antihuman IgM polyacrylamide immunobead reagent (Irvine Scientific (IS), Santa Ana, CA, USA) or with either soluble or immobilised rabbit anti-human IgM antibody (Jackson Immunoresearch (JI), Suffolk, UK); or goat $\mathrm{F}\left(\mathrm{ab}^{\prime}\right)_{2}$ anti-human IgM (MP Biomedicals (MB), Santa Ana, CA, USA; or SA). Rabbit anti-human IgA polyacrylamide immunobead reagent (IS) or either soluble or immobilised rabbit anti-human IgG antibody (JI); or goat $\mathrm{F}\left(\mathrm{ab}^{\prime}\right)_{2}$ anti-human IgG (MB); or goat $\mathrm{F}\left(\mathrm{ab}^{\prime}\right)_{2}$ anti-human IgA (SA) served as negative controls. Untreated (UT) cells kept in culture in IMDM complete without addition of any stimulation or control reagent were used as a reference population. After $24 \mathrm{~h}$ of culture or stimulation, cells were harvested for flow cytometric staining of cell surface markers and Qiazol lysis for mRNA isolation. Annexin V and 7-Aminoactinomycin D (7-AAD) labelling was performed after 24,48 and $72 \mathrm{~h}$ of stimulation.

Flow cytometry. The expression of surface molecules was analysed by flow cytometry, using the following monoclonal antibodies (mAbs): CD5-PECy7 (clone UCHT2, eBioscience, Vienna, Austria), CD19-allophycocyanin (APC) (clone LT19 Miltenyi Biotec, Leiden, The Netherlands), CD54 (ICAM-1)phycoerythrin (PE) (clone LB-2, BD Biosciences), CD62L (L-selectin)-fluorescein isothiocyanate (FITC) (clone DREG-56, eBioscience), CD184 (CXCR4)-PE (clone 12G5, BD Biosciences). A total of $10^{5} \mathrm{CD} 19^{+}$cells were incubated for $30 \mathrm{~min}$ at $4{ }^{\circ} \mathrm{C}$ in the dark with saturating concentrations of mAbs. Data acquisition was performed with a LSRII flow cytometer (BD Biosciences) and data analysis was performed using BD FACSDiva software.

Measurement of intracellular calcium flux. Calcium flux measurement was essentially performed as described by Gergely et al (1997). CD19 ${ }^{+}$cells were resuspended at $1 \times 10^{6} \mathrm{cells} \mathrm{ml}^{-1}$ in IMDM medium and incubated for $30 \mathrm{~min}$ at $37^{\circ} \mathrm{C}$ in the dark with $1 \mu \mathrm{M}$ Fluo-4-AM (Invitrogen). Subsequently, an equal amount of IMDM medium supplemented with 10\% FBS was added and cells were further incubated for $10 \mathrm{~min}$. Finally, cells were washed twice in IMDM supplemented with 5\% FBS and once in Hanks balanced salt solution (HBSS) flux buffer (Invitrogen) supplemented with $5 \% \mathrm{FBS}, 1.5 \mathrm{mM} \mathrm{CaCl}_{2}$ (SA) and buffered to pH 7.5 with $10 \mathrm{~mm}$ HEPES (SA). Cells were resuspended in HBSS flux buffer at a concentration of $1 \times 10^{6}$ cells $\mathrm{ml}^{-1}$ and kept at $37^{\circ} \mathrm{C}$ until analysis. Aliquots of $1 \times 10^{5}$ cells $(100 \mu \mathrm{l})$ were transferred into $200 \mu \mathrm{l}$ pre-warmed HBSS flux buffer in $12 \times 75 \mathrm{~mm}$ polystyrene tubes. Each tube was acquired for $30 \mathrm{~s}$ to measure background fluorescence. Subsequently, BCR stimulation was performed by addition of $100 \mu \mathrm{g} \mathrm{ml}^{-1}$ anti-human IgM polyacrylamide immunobead reagent (IS) or soluble rabbit anti-human IgM antibody (JI) and acquisition was continued for a total of $140 \mathrm{~s}$. Treatment with 
Table 1. Patient characteristics

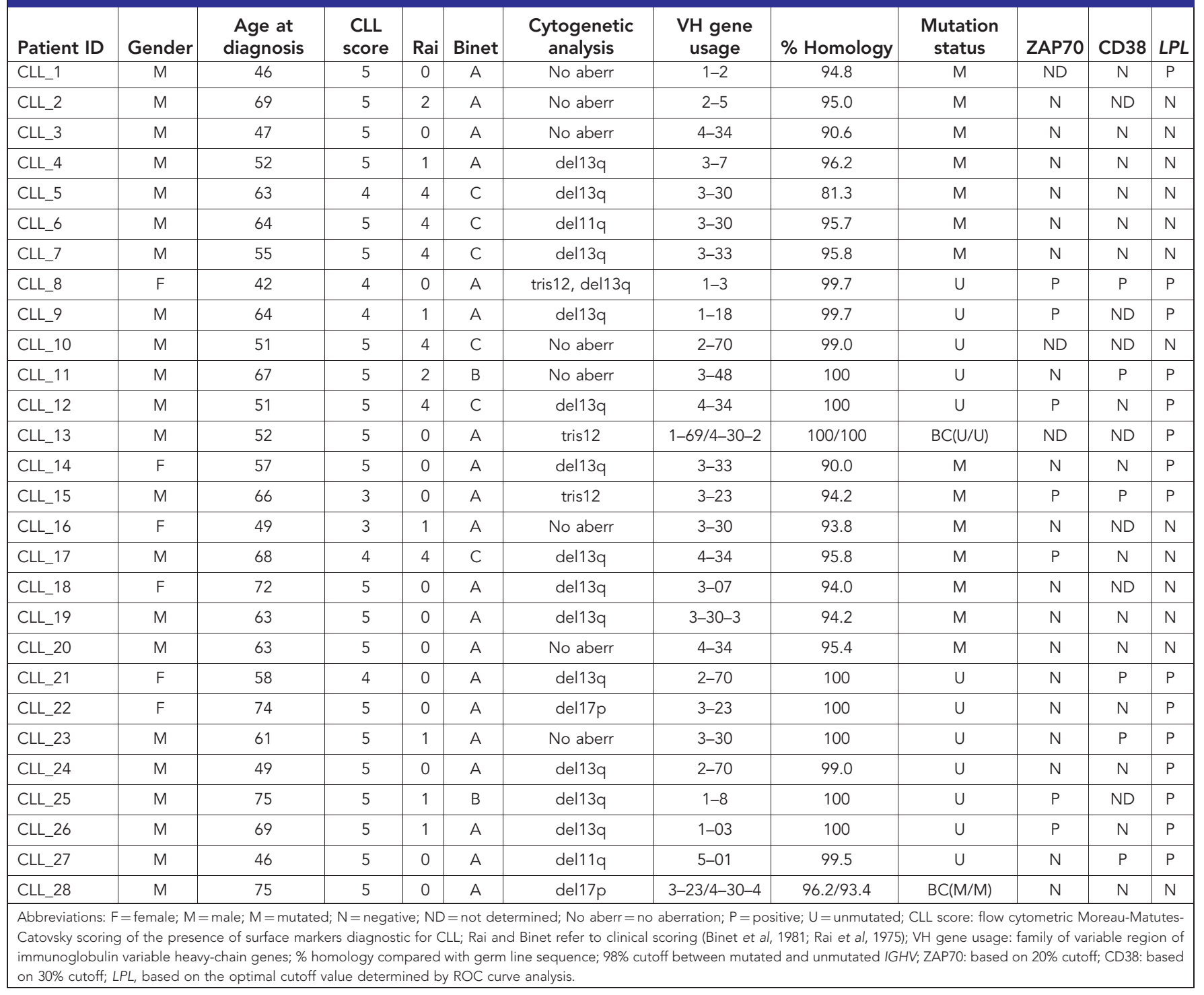

$5 \mu \mathrm{g} \mathrm{ml}^{-1}$ ionomycin served as positive control for calcium flux measurement.

Intracellular LPL staining. Flow cytometric analysis of intracellular LPL expression was performed using the protocol for intracellular ZAP70 staining described by Van Bockstaele et al (2006) optimised for LPL staining. In brief, $10^{5} \mathrm{CD} 19^{+}$cells were fixed and permeabilised using the Fix and Perm kit (ImTec Diagnostics, Antwerp, Belgium) according to the manufacturer's instructions. Cells were incubated with a monoclonal mouse antihuman LPL antibody (clone ab21356, Abcam, Cambridge, UK), washed twice, and incubated with PE-labelled goat anti-mouse antibody (Southern Biotech, Cambridge, UK). After washing, cells were stained for surface markers CD19-APC and CD5-PECy7. As a positive control for staining, we used CLL cells that overexpress the LPL protein after electroporation with in vitro transcribed (IVT) LPL mRNA conducted according to the protocol described by Van Bockstaele et al (2008).

Analysis of cell viability and apoptosis. After 24,48 and $72 \mathrm{~h}$ of stimulation, the level of apoptosis was determined by double staining with FITC-conjugated 7-AAD using the FITC Annexin V Apoptosis Detection Kit II (BD Pharmingen) following the manufacturer's instructions. Prior to Annexin V/7-AAD staining, cells were labelled with surface markers CD19-APC and CD5PECy7. Cells treated with $2.5 \mu \mathrm{M}$ staurosporine (Merck Millipore, Billerica, MA, USA) were used as a positive control for apoptosis.

RNA isolation, cDNA synthesis and real-time quantitative PCR. Total cellular RNA was extracted with the miRNeasy mini kit (Qiagen, Hilden, Germany) according to the supplier's instructions. Contaminating DNA was removed through DNase treatment using the DNase I, Amplification Grade, kit (Life Technologies, Merelbeke, Belgium). cDNA was synthesised from $1 \mu \mathrm{g}$ RNA with the Superscript III reverse transcriptase kit (Life Technologies). LPL mRNA expression levels were measured with qPCR as published before (Van Bockstaele et al, 2007). All other genes were measured using assays that were either SybrGreen based with primers described before for MYC (Mestdagh et al, 2010) and ACTB (Cheung et al, 2010) or probe hydrolysis based using either published primers and probe for ABL1 (Beillard et al, 2003) or an Assay-on-Demand gene expression assay for FOS (Applied Biosystems, Foster City, CA, USA), according to the manufacturer's instructions. All reactions were performed in duplicate on a LightCycler 480 (Roche, Basel, Switzerland) and each PCR run included non-template controls and a calibration 
curve of 6, three-fold dilutions of cDNA from stimulated CLL cells for quantification. $A C T B$ and $A B L 1$ housekeeping genes were used to normalise gene expression according to Pede et al (2013).

Data analysis and statistics. All statistical analyses were performed with GraphPad Prism 5 software (GraphPad Software, La Jolla, CA, USA). For statistical comparison between samples, the Mann-Whitney $U$-test was used for unpaired sample data, and the Wilcoxon signed-rank test was used for paired sample data. An effect was considered statistically significant at $P$-value $<0.05$. Bar diagrams and line plots were created using GraphPad Prism 5 software. Overlay histograms were made with FlowJo Software version 8 (FlowJo LLC, Ashland, OR, USA).

\section{RESULTS}

CLL cells respond differentially to soluble and immobilised antiIgM stimulation, irrespective of IGHV mutational status. The discrepancies found in literature concerning changes in gene expression and functional consequences upon BCR stimulation can, at least partially, be attributed to the lack of a standardised protocol to trigger the CLL BCR in vitro. We measured mRNA and protein expression of genes modulated by stimulation of the BCR in CLL, to assess the efficiency of different in vitro stimulation methods. Purified CD19 ${ }^{+}$B cells from 13 CLL patients (7 IGHV mutated (M) and $6 I G H V$ unmutated (U) CLL's) were stimulated with soluble or immobilised anti-IgM antibodies or $\mathrm{F}(\mathrm{ab})_{2}$ fragments at a concentration of 10 or $100 \mu \mathrm{g} \mathrm{ml}^{-1}$. UC were used as a reference, cells treated with anti-IgA or anti-IgG served as negative controls. After $24 \mathrm{~h}$ of BCR stimulation we measured the cell surface expression of proteins previously reported to be modulated by stimulation of the BCR in CLL (Quiroga et al, 2009; Vlad et al, 2009); CD54 (ICAM-1), CD19, CD62L (L-selectin) and CD184 (CXCR4) (Figure 1). Of all 13 CLL patients included in this study, one M-CLL case hardly responded to in vitro BCR stimulation and was excluded from further analysis. Comparing the mean fluorescence intensity (MFI) ratios of immobilised antiIgM stimulated samples with control (anti-IgG or anti-IgA) samples, we noticed a clear upregulation of CD54 (1A) and a firm downregulation of CD19 (1B) expression both at 10 and $100 \mu \mathrm{g} \mathrm{ml}^{-1}$, whereas the expression of both proteins was nearly unaffected by soluble anti-IgM even in the highest concentration. Expression of CD62L (1C) was decreased after immobilised antiIgM stimulation at both concentrations and after soluble anti-IgM at $100 \mu \mathrm{g} \mathrm{ml}^{-1}$. Comparing anti-IgM with control (anti-IgA/G) samples, a statistically significant $(P<0.05)$ change in CD54, CD19 and CD62L expression was induced by immobilised anti-IgM in all samples, whereas only in some conditions soluble anti-IgM induced significant effects. CD184 protein expression (1D) was significantly downregulated when immobilised anti-IgM was used at $100 \mu \mathrm{g} \mathrm{ml}^{-1}$, but at the lower concentration the effect was not significant in all conditions. When using soluble stimulation, only one source of anti-IgM (MB) induced a significant downregulation of $\mathrm{CD} 184$ at $100 \mu \mathrm{g} \mathrm{ml}^{-1}$. After $24 \mathrm{~h}$ of stimulation, we also measured mRNA expression levels for FOS, MYC and LPL, which were among the genes significantly upregulated by BCR stimulation in our previous study (Pede et al, 2013) (Figure 2). The expression profiles for FOS (2A) and MYC (2B) closely resemble the ones for CD54 and CD19. Indeed, soluble anti-IgM stimulation had no or only a very minor effect on FOS and MYC mRNA expression, whereas a considerable upregulation of both genes was observed after stimulation using immobilised anti-IgM. Five out of the six U-CLL cases included were considered LPL positive, measured by qPCR as described before (Van Bockstaele et al, 2007). The BCR induced LPL mRNA expression profile of these endogenously $L P L$-positive CLL patient samples measured after
$24 \mathrm{~h}(2 \mathrm{C})$, resembles the ones obtained for FOS and MYC and shows a clear upregulation only after $24 \mathrm{~h}$ of immobilised anti-IgM stimulation. The majority of M-CLL patient samples $(n=6)$ was, as expected, $L P L$ negative and no robust upregulation of $L P L$ mRNA expression levels after stimulation was observed (data not shown). These data were confirmed in an additional series of seven M-CLL and seven U-CLL cases stimulated with $100 \mu \mathrm{g} \mathrm{ml}^{-1}$ antihuman IgM immunobeads, or either immobilised or soluble antihuman IgM antibody (Supplementary Figures 1 and 2).

In general, immobilised BCR triggering using anti-IgM coupled beads at a concentration of $100 \mu \mathrm{g} \mathrm{ml}^{-1}$ induced the largest responses. At the lower concentration, other immobilised anti-IgM regimes were more effective. Remarkably, only minor differences were found in the response to 10 or $100 \mu \mathrm{g} \mathrm{ml}^{-1}$ immobilised antiIgM, suggesting saturation at $10 \mu \mathrm{g} \mathrm{ml}^{-1}$, whereas soluble antiIgM was usually more effective when used at a concentration of $100 \mu \mathrm{g} \mathrm{ml}^{-1}$. The specificity of binding of the different sources of anti-IgM was confirmed by including anti-IgA or anti-IgG-treated samples. Compared with UC, only MB (MB) anti-IgG affected the outcome compared with non-treated cells in some cases. Other anti-IgA or anti-IgG controls acted like untreated samples and can be used as reliable negative controls.

Although the gene expression profiles of CLL cells were found to be homogenous among IGHV M-CLL and U-CLL cases (Klein et al, 2001; Rosenwald et al, 2001), previous studies are inconclusive regarding responsiveness of M-CLL and U-CLL cells to BCR ligation in vitro (Petlickovski et al, 2005; Deglesne et al, 2006; Guarini et al, 2008; Vlad et al, 2009; Herishanu et al, 2011; Krysov et al, 2012). We previously reported that M-CLL and U-CLL cases are equally efficiently stimulated with anti-IgM beads, evaluated by FOS and MYC mRNA expression (Pede et al, 2013). In the current study, we aimed at validating these results with alternative stimulating agents. Although bead-based stimulation elicited the largest response at the level of protein and mRNA expression, we could show that both M-CLL and U-CLL cells responded to $\mathrm{BCR}$ triggering in vitro using other stimulation regimens as well. Indeed, the protein and mRNA expression profiles presented in Figures 1and 2, respectively, show a similar pattern in M-CLL and U-CLL cases. When the ratios of protein and mRNA expression levels in anti-IgM and control (A/G) stimulated samples $\left(100 \mu \mathrm{g} \mathrm{ml}^{-1}\right)$ were compared in M-CLL and U-CLL cases, significant differences in fold changes were observed only in very few conditions using immobilised anti-IgM triggering (Supplementary Figure 3).

Next to protein and mRNA expression, we measured induction of calcium flux as a direct read-out of BCR triggering in three $\mathrm{M}-\mathrm{CLL}$ and three U-CLL using either $100 \mu \mathrm{g} \mathrm{ml}^{-1}$ anti-IgM immunobeads or soluble anti-IgM (Supplementary Figure 4). Stimulation using anti-IgM antibody coated to culture plates was not compatible with this assay. Both M-CLL and U-CLL cases were able to mount a calcium flux upon robust BCR stimulation using bead-based immobilised anti-IgM, thereby confirming again our observations on protein and mRNA level. Soluble anti-IgM induced a weaker response that faded quickly.

Evaluation of LPL protein expression in IgM-stimulated CLL cells by flow cytometry. As mRNA levels of $L P L$ were clearly induced in U-CLL, we asked whether this resulted in increased protein expression. To do so, we optimised an intracellular LPL protein staining protocol for flow cytometry in CLL cells. For validation, we used CLL cells overexpressing LPL protein after electroporation with IVT LPL mRNA (Figure 3A). This flow cytometric staining procedure was not sensitive enough to detect LPL protein in endogenously LPL positive CLL cells and consequently did not allow distinguishing them from $L P L$-negative CLL cells (data not shown). Only when CLL cells were robustly stimulated using anti-IgM-coated beads, we managed to stain LPL 
A

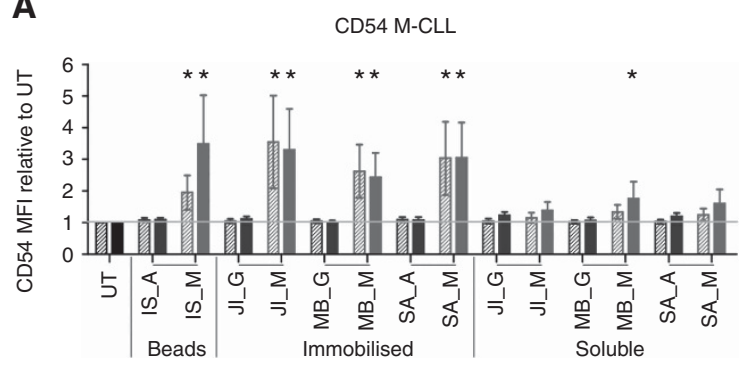

B

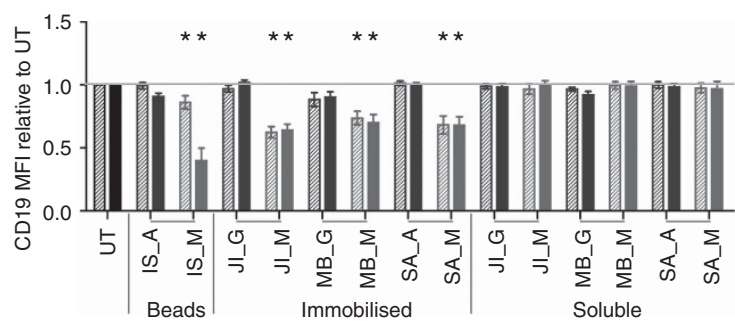

C

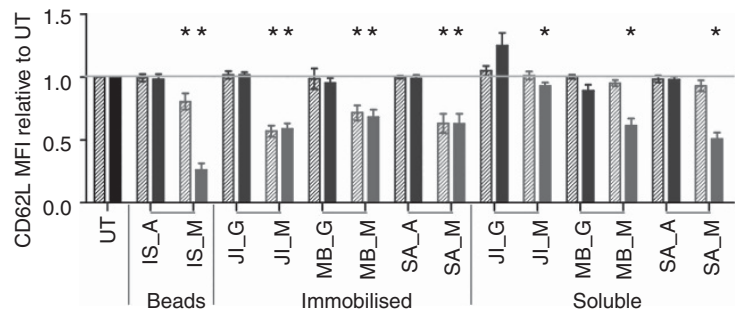

CD184 M-CLL

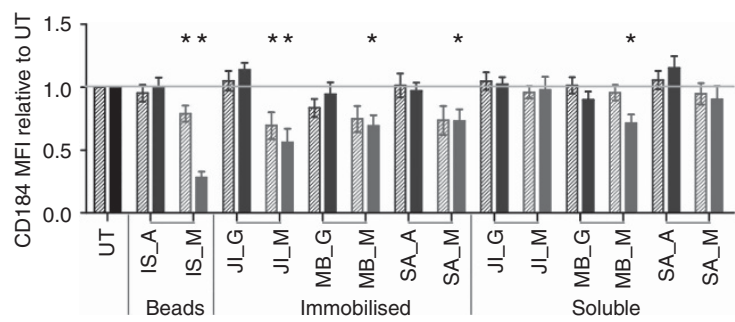

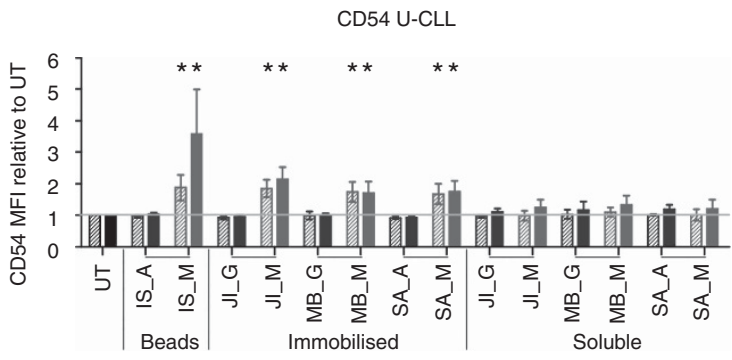

CD19 U-CLL

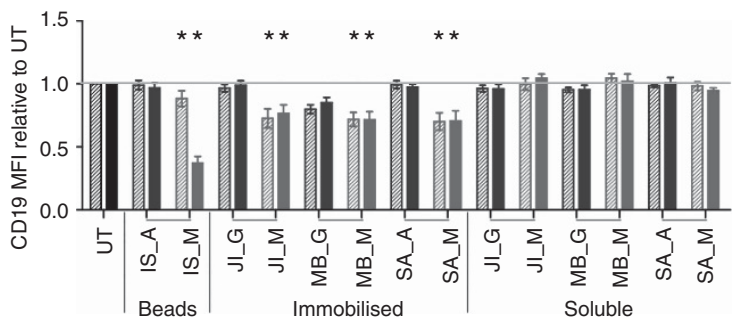

CD62L U-CLL

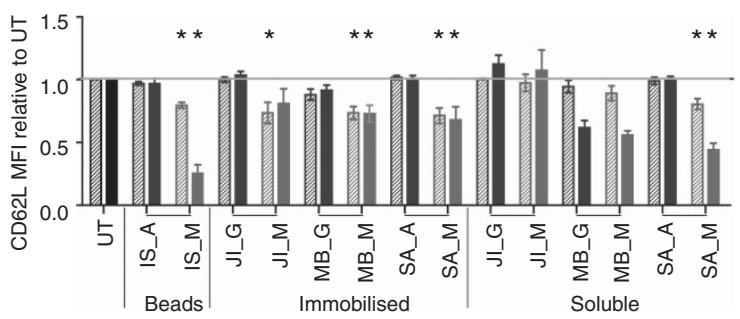

CD184 U-CLL

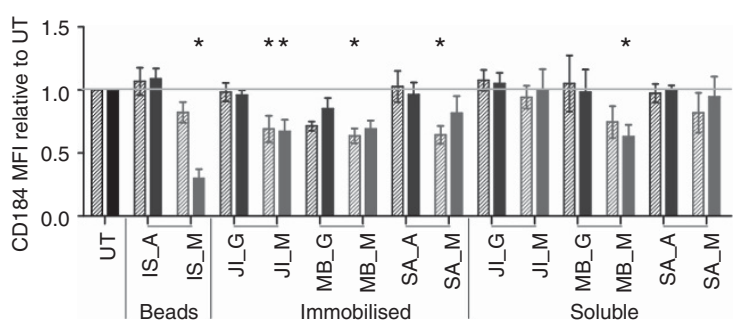

Figure 1. Cell surface expression of proteins modulated by soluble and immobilised BCR stimulation of CLL cells. Cell surface expression of CD54 (A), CD19 (B), CD62L (C) and CD184 (D) in mutated (M; $n=6$; left panel) and unmutated ( $\mathrm{U} ; n=6$; right panel) CLL cells after 24h of BCR stimulation using anti-lgM coupled beads, immobilised or soluble anti-lgM in two concentrations (red hatched bars; $10 \mu \mathrm{g} \mathrm{ml}^{-1}$, red solid bars; $100 \mu \mathrm{g} \mathrm{ml}^{-1}$ ). Anti-lgA (A) or Anti-lgG (G) served as negative controls (blue hatched bars; $10 \mu \mathrm{g} \mathrm{ml}^{-1}$, blue solid bars; $100 \mu \mathrm{g} \mathrm{ml}^{-1}$ ). Bar diagrams display the mean fluorescence intensity (MFI) relative to UT (black bars) (mean \pm s.e.m.). IS, JI, MB and SA refer to the source of stimulation reagent (see Materials and Methods). * above anti-lgM samples indicate statistically significant differences between control (anti-lgA/lgG) and anti-lgM stimulation, with $P<0.05$. The horizontal grey line represents a ratio of 1 . A full color version of this figure is available at the British Journal of Cancer journal online.

protein. As shown in Figure 3, both M-CLL (3B) and U-CLL (3C) cells showed a clear shift in LPL MFI after $24 \mathrm{~h}$ of anti-IgM stimulation compared with unstimulated or anti-IgA-stimulated conditions. Stimulating CLL cells with any other anti-IgM reagent, either immobilised or in solution, did not result in detectable LPL protein by intracellular staining (data not shown).

Effect of soluble and immobilised anti-IgM on CLL cell survival. In addition, we investigated the functional effects of BCR stimulation in CLL. As expected, after $24 \mathrm{~h}$ of culture we were not able to show induction of proliferation in a selection of samples measured by intracellular Ki67 staining, even after strong stimulation using anti-IgM beads (data not shown). Some studies also report that BCR stimulation influences CLL cell viability.
Whether in vitro BCR triggering induces apoptosis or protects CLL cells from undergoing apoptosis is however not clear. The effect of BCR triggering on CLL cell survival in vitro was assessed by Annexin V/7-AAD labelling after $24 \mathrm{~h}$ of stimulation (Supplementary Figure 5A and B). The levels of apoptotic cells varied widely among the different CLL samples (range 8.6-58.9\%).

Although not always significant, we observed a trend of reduced apoptotic levels only in M-CLL cells when immobilised anti-IgM was used. For soluble stimulation, the effect was not clear and rather reagent dependent. In U-CLL cells the apoptotic levels fluctuated over all conditions without an obvious trend. In an independent series of seven M-CLL and seven U-CLL cases, levels of apoptotic cells were measured at later time points (48 and $72 \mathrm{~h}$ ) as well (Supplementary Figure 5C and D). In M-CLL, a significant 
A

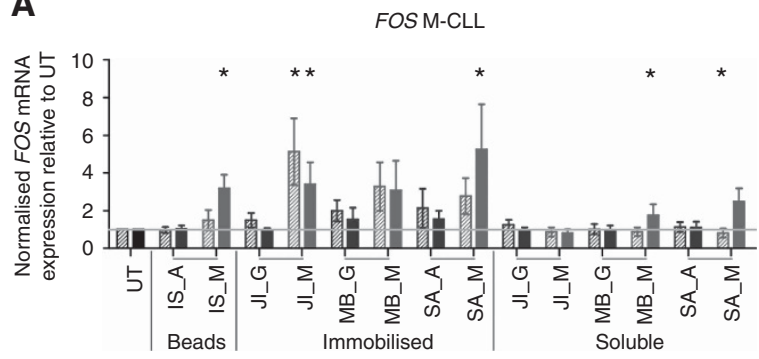

B

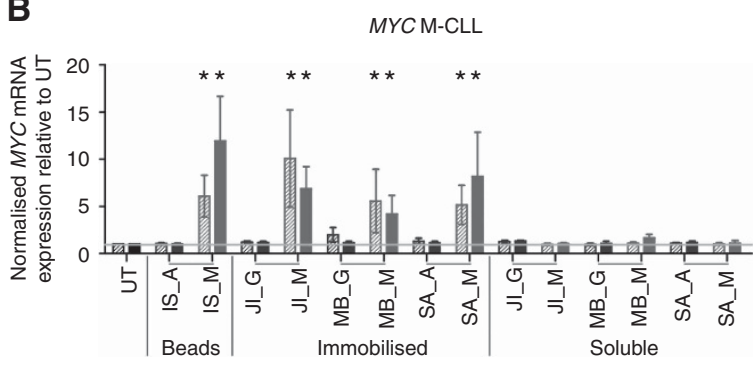

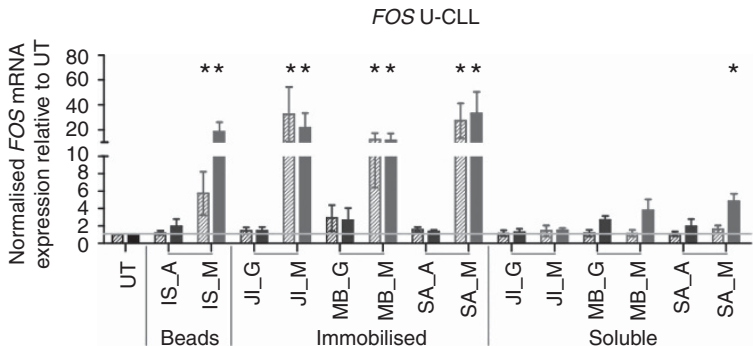

MYCU-CLL

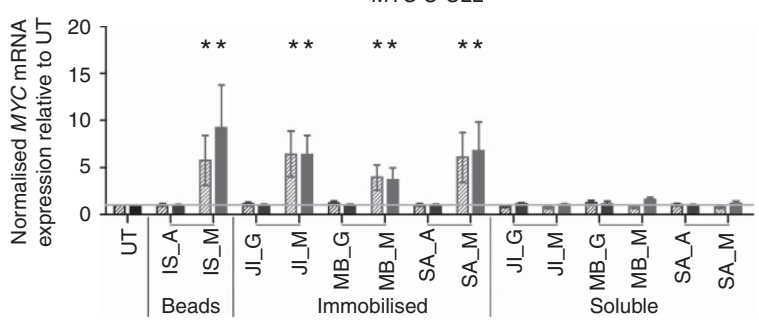

C

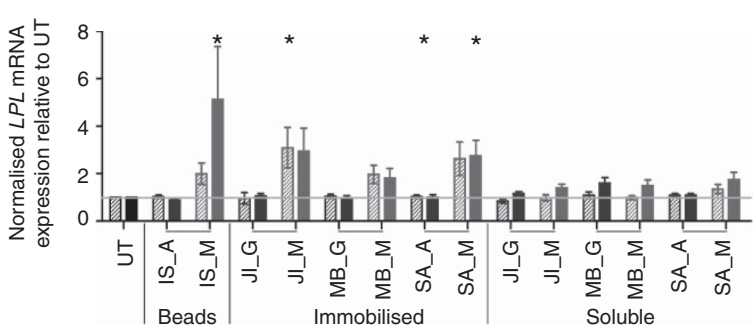

Figure 2. Immobilised BCR triggering affects mRNA expression of FOS, MYC and LPL. Expression of FOS (A), MYC (B) and LPL (C) mRNA in CLL cells stimulated with $10 \mu \mathrm{g} \mathrm{ml}^{-1}$ or $100 \mu \mathrm{g} \mathrm{ml}^{-1}$ anti-lgM-coated beads, immobilised anti-lgM or soluble anti-lgM for $24 \mathrm{~h}$ (red hatched bars; $10 \mu \mathrm{g} \mathrm{ml}^{-1}$, red solid bars; $\left.100 \mu \mathrm{g} \mathrm{ml}^{-1}\right)$. Left panels show expression levels in mutated CLL cases $(M ; n=6)$, right panels in unmutated CLL cases $(U ; n=6)$. Anti-lgA (A) or Anti-lgG (G) served as negative controls (blue hatched bars; $10 \mu \mathrm{g} \mathrm{ml}^{-1}$, blue solid bars; $100 \mu \mathrm{g} \mathrm{ml}{ }^{-1}$ ). Analysis of $L P L$ mRNA expression response was performed in unmutated endogenously LPL positive CLL samples only $(n=5)$. Bars display normalised mRNA expression levels relative to UT (black bars) (mean \pm s.e.m.). IS, JI, MB, SA refer to the source of stimulation reagent (see Materials and Methods). * above anti-lgM samples indicate statistically significant differences between control (anti-lgA/lgG) and anti-lgM stimulation, with $P<0.05$.

The horizontal grey line represents a ratio of 1 . A full color version of this figure is available at the British Journal of Cancer journal online.

protective effect was observed in case of immobilised anti-IgM stimulation after $24 \mathrm{~h}$ and both with immobilised and soluble antiIgM after 48 and $72 \mathrm{~h}$. However, in unmutated CLL, significantly lower levels of apoptotic cells were only observed after $48 \mathrm{~h}$ with anti-IgM coated beads, and after $72 \mathrm{~h}$ with anti-IgM coated to culture plates as well.

The degree of protection from apoptosis differed significantly between M-CLL and U-CLL cases only when the BCR was stimulated with anti-IgM coated to culture plates $\left(100 \mu \mathrm{g} \mathrm{ml}^{-1}\right)$ for 48 and 72 h (Supplementary Figure 6).

\section{DISCUSSION}

In this study, we evaluated the efficiency of soluble and immobilised anti-IgM to stimulate the CLL BCR in vitro and found that immobilised anti-IgM triggers induce more powerful BCR stimulation compared with soluble anti-IgM, regardless of IGHV mutation status. As a read-out for responsiveness of CLL cells to stimulation, we measured protein and mRNA expression of genes modulated upon BCR triggering. The observed downregulation of CD62L and CD184 surface expression was observed before by Vlad et al (2009), but is discordant with the findings of (Quiroga et al, 2009) who showed that anti-IgM increases the expression of several adhesion molecules, among which CD62L. Next to this, both groups do not agree on the effect of BCR triggering upon CXCL12-induced migration of CLL cells. According to Quiroga et al these discrepancies can be attributed to the fact that they used soluble anti-IgM, whereas Vlad et al. used immobilised anti-IgM. We found a clear downregulation of CD62L using both soluble and immobilised anti-IgM at a concentration of $100 \mu \mathrm{g} \mathrm{ml}^{-1}$. At a concentration of $10 \mu \mathrm{g} \mathrm{ml}^{-1}$, which was used by Quiroga et al and Vlad et al, the downregulation by soluble anti-IgM was less obvious; however, we certainly did not find an upregulaton as Quiroga et al reported. Differences in antibody specificity, affinity or avidity are not responsible for these contrasting results either, as we observed the same results using four different sources of anti-IgM, among them the one used by Quiroga et al and Vlad et al. Next to CD62L, Quiroga et al also reported BCR-induced CD54 upregulation, which was confirmed by our data; however, only when immobilised anti-IgM was used. The same holds true for CD19. Indeed, we did not find any change in cell surface expression of CD54 and CD19 in response to soluble anti-IgM, whereas significant responses were observed after immobilised BCR triggering. Also for CD62L and CD184, significant responses were induced mainly with immobilised anti-IgM. Overall, the strongest effects were obtained with anti-IgM-coupled beads, representing immobilised anti-IgM antibodies. These beads were used in a 
A

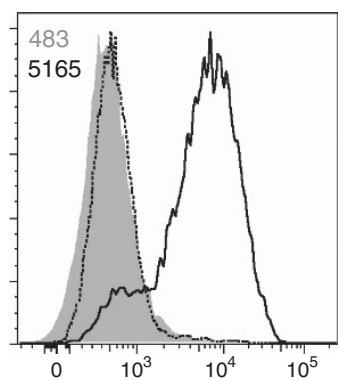

B

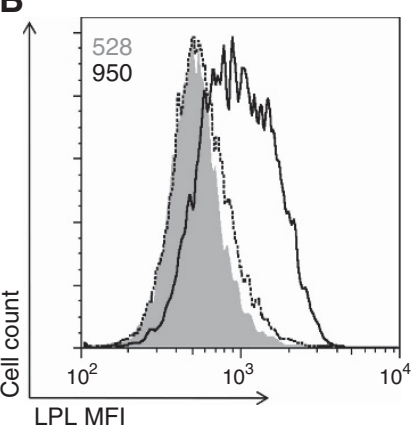

C

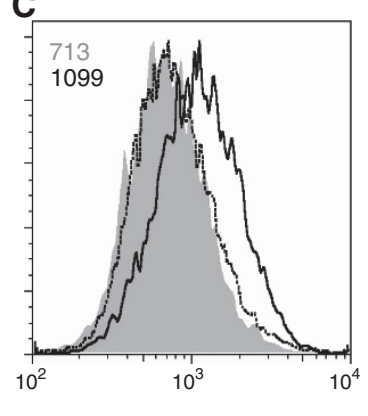

Figure 3. Powerful anti-lgM stimulation allows detection of LPL protein through flow cytometric staining in CLL cells. (A) Overlay histogram depicts the mean fluorescence intensity (MFI) of CLL cells stained for intracellular LPL protein, $3 \mathrm{~h}$ after electroporation with IVT LPL mRNA (black line). UT (black dotted line) and cells electroporated with IVT $\triangle$ NGFR mRNA (solid grey histogram) were included as controls. The numbers in the left upper corner indicate the MFI values for the $\triangle N G F R$ mRNA (grey) and LPL (black)-electroporated samples. (B, C) Histogram overlays of the MFI of CLL cells of a representative mutated $(M ; B)$ and unmutated $(U ; C)$ case stained for intracellular LPL protein, $24 \mathrm{~h}$ after stimulation with anti-lgM coated beads (black line). Untreated cells (black dotted line) or cells treated with anti-lgA-coated beads (grey solid histogram) were included as negative controls. The numbers in the left upper corner indicate the MFI values for the anti-lgA (grey) and anti-lgM (black)-stimulated samples.

previous study where we investigated the transcriptional response upon BCR triggering and found both in M-CLL and U-CLL cases an increased expression of genes associated with BCR activation, including FOS and MYC (Pede et al, 2013). In the present study we were able to confirm this BCR-driven induction of FOS and MYC mRNA expression, only when immobilised anti-IgM was used, thereby confirming our protein expression data. Considering the fact that the anti-IgM (and anti-IgA) beads are no longer manufactured, we show here that valuable alternatives for beadbased BCR stimulation are available, that are proven to be very efficient even at a lower concentration.

The upregulation of MYC expression after BCR stimulation was reported by others before, by using both immobilised or soluble anti-IgM (Petlickovski et al, 2005; Krysov et al, 2012). However, Krysov et al, who used soluble anti-IgM, looked at MYC protein expression only at 3 and $6 \mathrm{~h}$ after stimulation and did not include later time points. The differences in response following soluble and immobilised BCR triggering may indeed be attributed to the rapid internalisation of soluble anti-IgM by endocytosis, inducing a rather transient response, whereas immobilised anti-IgM induces a more sustained triggering, resulting in a more complete and stable response. In this view, cell surface protein and mRNA expression might be modulated by soluble anti-IgM more rapidly. We could, however, not confirm this by calcium flux measurement upon BCR triggering.

Although conflicting results are published, we show that both M-CLL and U-CLL respond to (soluble and immobilised) anti-IgM stimulation. The protein and mRNA expression profiles of M-CLL cases closely resemble the ones observed in U-CLL cases, showing that both have the ability to respond to in vitro BCR stimulation. We do not exclude that some patients respond better to anti-IgM stimulation than others, but the ability to be stimulated does not necessarily depend on $I G H V$ mutation status. It was shown before that CLL patients express variable levels of surface IgM (sIgM), with circulating U-CLL cells showing a higher sIgM expression than M-CLL, giving rise to different degrees of responsiveness among both subgroups.

In addition to FOS and $M Y C$, we also evaluated the levels of $L P L$ mRNA expression. $L P L$ is an established poor prognostic marker in CLL and was shown to be induced by BCR triggering (Pallasch et al, 2008; Herishanu et al, 2011; Pede et al, 2013). We observed a significant upregulation of LPL mRNA after immobilised anti-IgM stimulation in endogenously $L P L$-positive CLL samples, thereby confirming again the robustness of immobilised BCR triggering. Again, the strongest upregulation of LPL mRNA expression was induced by bead-based stimulation of the BCR, which also increased LPL protein expression to levels detectable through intracellular flow cytometric staining using our optimised protocol. This staining procedure was, however, not sensitive enough to distinguish endogenously expressed $L P L$-positive from $L P L$ negative patient samples and will thus not allow determining a CLL patient's status for this prognostic marker as is the case for ZAP70.

Next to the effect on gene expression, there is no consensus on the functional consequences of in vitro BCR activation in CLL cells. It is believed that in vivo BCR signalling contributes to the survival and proliferation of the malignant clone. Here, we could not show BCR related induction of proliferation, although we reported active proliferation in anti-IgM-stimulated samples before (Pede et al, 2013). This discrepancy is probably due to the use of a different read-out and a different time point of analysis. Indeed, before we analysed samples after $48 \mathrm{~h}$ of stimulation using DRAQ5 staining, whereas in the present study we stained for Ki67 already after $24 \mathrm{~h}$ of stimulation, which is probably too early to observe a significant effect of stimulation upon proliferation. Protection from spontaneous apoptosis in vitro after immobilised BCR triggering was reported repeatedly before. When soluble anti-IgM was used, however, both induction and inhibition of spontaneous apoptosis after stimulation have been observed (Petlickovski et al, 2005; Deglesne et al, 2006; Quiroga et al, 2009). We did not observe a clear difference between soluble or immobilised BCR stimulation regarding apoptosis after $24 \mathrm{~h}$. At later time points we found that both immobilised and soluble anti-IgM protected CLL cells from spontaneous apoptosis, presumably mimicking the effect of in vivo BCR triggering. Although the effect was more pronounced in case of immobilised BCR stimulation, induction of apoptosis was not observed in any of the conditions tested.

The protective effect of BCR stimulation was seen both in M-CLL and U-CLL, but in M-CLL it was induced more rapidly and more strongly. Even in case of soluble anti-IgM significantly lower levels of apoptotic cells could be observed in M-CLL, in contrast to U-CLL who only showed a significant response in case of immobilised BCR triggering. This is probably because of the fact that U-CLL cells are more resistant to spontaneous apoptosis compared with M-CLL cells and longer incubation times and/or more robust triggering of the BCR are needed before a significant response can be observed.

In the present study we show that immobilised BCR triggering induces a more robust response compared with soluble triggers. The use of immobilised anti-IgM is preferred over soluble anti-IgM when trying to unravel the role of BCR triggering in the CLL pathogenesis. Indeed, immobilised BCR-triggering reflects better 
what CLL cells experience in vivo in the microenvironment, based on gene expression data obtained in CLL cells isolated from lymph nodes (Herishanu et al, 2011). As we show here that both M-CLL and $\mathrm{U}-\mathrm{CLL}$ respond to in vitro anti-IgM BCR stimulation, the differences in gene expression profiles previously observed in M-CLL versus U-CLL might not be due to cell intrinsic differences, but rather a reflection of differential in vivo BCR triggering. Unmutated BCRs might have a higher specificity for antigens inducing more repetitive or sustained signalling comparable to immobilised anti-IgM, or U-CLL cells might reside more in areas with a higher chance of encountering such antigens in vivo, ultimately resulting in stronger BCR signalling and distinct clinical and biological behaviour compared with M-CLL.

\section{ACKNOWLEDGEMENTS}

We thank the patients for sample donation. This work was supported by grants from the Research Foundation Flanders (FWO) to JP and BV. AR is a PhD fellow and BV is a Senior Clinical Investigator of the FWO.

\section{CONFLICT OF INTEREST}

The authors declare no conflict of interest.

\section{REFERENCES}

Beillard E, Pallisgaard N, van der Velden VH, Bi W, Dee R, van der Schoot E, Delabesse E, Macintyre E, Gottardi E, Saglio G, Watzinger F, Lion T, van Dongen JJ, Hokland P, Gabert J (2003) Evaluation of candidate control genes for diagnosis and residual disease detection in leukemic patients using 'real-time' quantitative reverse-transcriptase polymerase chain reaction (RQ-PCR) - a Europe against cancer program. Leukemia 17(12): 2474-2486.

Binet JL, Auquier A, Dighiero G, Chastang C, Piguet H, Goasguen J, Vaugier G, Potron G, Colona P, Oberling F, Thomas M, Tchernia G, Jacquillat C, Boivin P, Lesty C, Duault MT, Monconduit M, Belabbes S, Gremy F (1981) A new prognostic classification of chronic lymphocytic leukemia derived from a multivariate survival analysis. Cancer 48(1): 198-206.

Burger JA, Gribben JG (2014) The microenvironment in chronic lymphocytic leukemia (CLL) and other B cell malignancies: insight into disease biology and new targeted therapies. Semin Cancer Biol 24: 71-81.

Burger JA, Quiroga MP, Hartmann E, Burkle A, Wierda WG, Keating MJ, Rosenwald A (2009) High-level expression of the T-cell chemokines CCL3 and CCL4 by chronic lymphocytic leukemia B cells in nurselike cell cocultures and after BCR stimulation. Blood 113(13): 3050-3058.

Capello D, Guarini A, Berra E, Mauro FR, Rossi D, Ghia E, Cerri M, Logan J, Foa R, Gaidano G (2004) Evidence of biased immunoglobulin variable gene usage in highly stable B-cell chronic lymphocytic leukemia. Leukemia 18(12): 1941-1947.

Cheung VG, Nayak RR, Wang IX, Elwyn S, Cousins SM, Morley M, Spielman RS (2010) Polymorphic cis- and trans-regulation of human gene expression. PLoS Biol 8: 9.

Chiorazzi N, Rai KR, Ferrarini M (2005) Chronic lymphocytic leukemia. N Engl J Med 352(8): 804-815.

Crespo M, Bosch F, Villamor N, Bellosillo B, Colomer D, Rozman M, Marce S, Lopez-Guillermo A, Campo E, Montserrat E (2003) ZAP-70 expression as a surrogate for immunoglobulin-variable-region mutations in chronic lymphocytic leukemia. $N$ Engl J Med 348(18): 1764-1775.

Damle RN, Wasil T, Fais F, Ghiotto F, Valetto A, Allen SL, Buchbinder A, Budman D, Dittmar K, Kolitz J, Lichtman SM, Schulman P, Vinciguerra VP, Rai KR, Ferrarini M, Chiorazzi N (1999) Ig V gene mutation status and CD38 expression as novel prognostic indicators in chronic lymphocytic leukemia. Blood 94(6): 1840-1847.

de Rooij MF, Kuil A, Geest CR, Eldering E, Chang BY, Buggy JJ, Pals ST, Spaargaren M (2012) The clinically active BTK inhibitor PCI-32765 targets B-cell receptor- and chemokine-controlled adhesion and migration in chronic lymphocytic leukemia. Blood 119(11): 2590-2594.

Deglesne PA, Chevallier N, Letestu R, Baran-Marszak F, Beitar T, Salanoubat C, Sanhes L, Nataf J, Roger C, Varin-Blank N, Ajchenbaum-Cymbalista F (2006) Survival response to B-cell receptor ligation is restricted to progressive chronic lymphocytic leukemia cells irrespective of Zap70 expression. Cancer Res 66(14): 7158-7166.

Gergely L, Cook L, Agnello V (1997) A simplified method for Ca2 + flux measurement on isolated human B cells that uses flow cytometry. Clin Diagn Lab Immunol 4(1): 70-74.

Guarini A, Chiaretti S, Tavolaro S, Maggio R, Peragine N, Citarella F, Ricciardi MR, Santangelo S, Marinelli M, De Propris MS, Messina M, Mauro FR, Del Giudice I, Foa R (2008) BCR ligation induced by IgM stimulation results in gene expression and functional changes only in $\operatorname{IgV}$ $\mathrm{H}$ unmutated chronic lymphocytic leukemia (CLL) cells. Blood 112(3): 782-792.

Hamblin TJ, Davis Z, Gardiner A, Oscier DG, Stevenson FK (1999) Unmutated $\operatorname{Ig~} \mathrm{V}(\mathrm{H})$ genes are associated with a more aggressive form of chronic lymphocytic leukemia. Blood 94(6): 1848-1854.

Heintel D, Kienle D, Shehata M, Krober A, Kroemer E, Schwarzinger I, Mitteregger D, Le T, Gleiss A, Mannhalter C, Chott A, Schwarzmeier J, Fonatsch C, Gaiger A, Dohner H, Stilgenbauer S, Jager U (2005) High expression of lipoprotein lipase in poor risk B-cell chronic lymphocytic leukemia. Leukemia 19(7): 1216-1223.

Herishanu Y, Perez-Galan P, Liu D, Biancotto A, Pittaluga S, Vire B, Gibellini F, Njuguna N, Lee E, Stennett L, Raghavachari N, Liu P, McCoy JP, Raffeld M, Stetler-Stevenson M, Yuan C, Sherry R, Arthur DC, Maric I, White T, Marti GE, Munson P, Wilson WH, Wiestner A (2011) The lymph node microenvironment promotes B-cell receptor signaling, NF-kappaB activation, and tumor proliferation in chronic lymphocytic leukemia. Blood 117(2): 563-574.

Hoellenriegel J, Meadows SA, Sivina M, Wierda WG, Kantarjian H, Keating MJ, Giese N, O’Brien S, Yu A, Miller LL, Lannutti BJ, Burger JA (2011) The phosphoinositide 3'-kinase delta inhibitor, CAL-101, inhibits B-cell receptor signaling and chemokine networks in chronic lymphocytic leukemia. Blood 118(13): 3603-3612.

Klein U, Tu Y, Stolovitzky GA, Mattioli M, Cattoretti G, Husson H, Freedman A, Inghirami G, Cro L, Baldini L, Neri A, Califano A, Dalla-Favera R (2001) Gene expression profiling of B cell chronic lymphocytic leukemia reveals a homogeneous phenotype related to memory B cells. J Exp Med 194(11): 1625-1638.

Krysov S, Dias S, Paterson A, Mockridge CI, Potter KN, Smith KA, Ashton-Key M, Stevenson FK, Packham G (2012) Surface IgM stimulation induces MEK1/2-dependent MYC expression in chronic lymphocytic leukemia cells. Blood 119(1): 170-179.

Messmer BT, Albesiano E, Efremov DG, Ghiotto F, Allen SL, Kolitz J, Foa R, Damle RN, Fais F, Messmer D, Rai KR, Ferrarini M, Chiorazzi N (2004) Multiple distinct sets of stereotyped antigen receptors indicate a role for antigen in promoting chronic lymphocytic leukemia. J Exp Med 200(4): 519-525.

Mestdagh P, Fredlund E, Pattyn F, Schulte JH, Muth D, Vermeulen J, Kumps C, Schlierf S, De Preter K, Van Roy N, Noguera R, Laureys G, Schramm A, Eggert A, Westermann F, Speleman F, Vandesompele J (2010) MYCN/c-MYC-induced microRNAs repress coding gene networks associated with poor outcome in MYCN/c-MYC-activated tumors. Oncogene 29(9): 1394-1404.

Niiro H, Clark EA (2002) Regulation of B-cell fate by antigen-receptor signals. Nat Rev Immunol 2(12): 945-956.

Pallasch CP, Schwamb J, Konigs S, Schulz A, Debey S, Kofler D, Schultze JL, Hallek M, Ultsch A, Wendtner CM (2008) Targeting lipid metabolism by the lipoprotein lipase inhibitor orlistat results in apoptosis of B-cell chronic lymphocytic leukemia cells. Leukemia 22(3): 585-592.

Pede V, Rombout A, Vermeire J, Naessens E, Mestdagh P, Robberecht N, Vanderstraeten H, Van Roy N, Vandesompele J, Speleman F, Philippe J, Verhasselt B (2013) CLL cells respond to B-Cell receptor stimulation with a microRNA/mRNA signature associated with MYC activation and cell cycle progression. PLoS One 8(4): e60275.

Petlickovski A, Laurenti L, Li X, Marietti S, Chiusolo P, Sica S, Leone G, Efremov DG (2005) Sustained signaling through the B-cell receptor induces Mcl-1 and promotes survival of chronic lymphocytic leukemia B cells. Blood 105(12): 4820-4827.

Quiroga MP, Balakrishnan K, Kurtova AV, Sivina M, Keating MJ, Wierda WG, Gandhi V, Burger JA (2009) B-cell antigen receptor 
signaling enhances chronic lymphocytic leukemia cell migration and survival: specific targeting with a novel spleen tyrosine kinase inhibitor, R406. Blood 114(5): 1029-1037.

Rai KR, Sawitsky A, Cronkite EP, Chanana AD, Levy RN, Pasternack BS (1975) Clinical staging of chronic lymphocytic leukemia. Blood 46(2): 219-234.

Rosenwald A, Alizadeh AA, Widhopf G, Simon R, Davis RE, Yu X, Yang L, Pickeral OK, Rassenti LZ, Powell J, Botstein D, Byrd JC, Grever MR, Cheson BD, Chiorazzi N, Wilson WH, Kipps TJ, Brown PO, Staudt LM (2001) Relation of gene expression phenotype to immunoglobulin mutation genotype in B cell chronic lymphocytic leukemia. J Exp Med 194(11): 1639-1647.

Sivina M, Hartmann E, Kipps TJ, Rassenti L, Krupnik D, Lerner S, LaPushin R, Xiao L, Huang X, Werner L, Neuberg D, Kantarjian H, O'Brien S, Wierda WG, Keating MJ, Rosenwald A, Burger JA (2011) CCL3 (MIP-1alpha) plasma levels and the risk for disease progression in chronic lymphocytic leukemia. Blood 117(5): 1662-1669.

van't Veer MB, Brooijmans AM, Langerak AW, Verhaaf B, Goudswaard CS, Graveland WJ, van Lom K, Valk PJM (2006) The predictive value of lipoprotein lipase for survival in chronic lymphocytic leukemia. Haematologica 91(1): 56-63.

Van Bockstaele F, Janssens A, Piette A, Callewaert F, Pede V, Offner F, Verhasselt B, Philippe J (2006) Kolmogorov-Smirnov statistical test for analysis of ZAP-70 expression in B-CLL, compared with quantitative PCR and $\operatorname{IgV}(\mathrm{H})$ mutation status. Cytometry B Clin Cytom 70(4): 302-308.

Van Bockstaele F, Pede V, Janssens A, Callewaert F, Offner F, Verhasselt B, Philippe J (2007) Lipoprotein lipase mRNA expression in whole blood is a prognostic marker in B cell chronic lymphocytic leukemia. Clin Chem 53(2): 204-212.
Van Bockstaele F, Pede V, Naessens E, Van Coppernolle S, Van Tendeloo V, Verhasselt B, Philippe J (2008) Efficient gene transfer in CLL by mRNA electroporation. Leukemia 22(2): 323-329.

van Dongen JJ, Lhermitte L, Bottcher S, Almeida J, van der Velden VH, Flores-Montero J, Rawstron A, Asnafi V, Lecrevisse Q, Lucio P, Mejstrikova E, Szczepanski T, Kalina T, de Tute R, Bruggemann M, Sedek L, Cullen M, Langerak AW, Mendonca A, Macintyre E, Martin-Ayuso M, Hrusak O, Vidriales MB, Orfao A (2012) EuroFlow antibody panels for standardized n-dimensional flow cytometric immunophenotyping of normal, reactive and malignant leukocytes. Leukemia 26(9): 1908-1975.

Vlad A, Deglesne PA, Letestu R, Saint-Georges S, Chevallier N, Baran-Marszak F, Varin-Blank N, Ajchenbaum-Cymbalista F, Ledoux D (2009) Down-regulation of CXCR4 and CD62L in chronic lymphocytic leukemia cells is triggered by B-cell receptor ligation and associated with progressive disease. Cancer Res 69(16): 6387-6395.

Wiestner A, Rosenwald A, Barry TS, Wright G, Davis RE, Henrickson SE, Zhao H, Ibbotson RE, Orchard JA, Davis Z, Stetler-Stevenson M, Raffeld M, Arthur DC, Marti GE, Wilson WH, Hamblin TJ, Oscier DG, Staudt LM (2003) ZAP-70 expression identifies a chronic lymphocytic leukemia subtype with unmutated immunoglobulin genes, inferior clinical outcome, and distinct gene expression profile. Blood 101(12): 4944-4951.

This work is published under the standard license to publish agreement. After 12 months the work will become freely available and the license terms will switch to a Creative Commons AttributionNonCommercial-Share Alike 4.0 Unported License.

Supplementary Information accompanies this paper on British Journal of Cancer website (http://www.nature.com/bjc) 